\title{
Visualization Tests on Variation of Scour Front under a Pipeline in Steady Currents
}

\author{
Liquan Xie ${ }^{1}$, Yehui Zhu ${ }^{1, *}$ and Tsung-Chow $\mathrm{Su}^{2}$ \\ College of Civil Engineering, Tongji University, Shanghai 200092, China; xie_liquan@tongji.edu.cn \\ 2 Department of Ocean and Mechanical Engineering, Florida Atlantic University, Boca Raton, FL 33431, USA; \\ su@fau.edu \\ * Correspondence: yehui_zhu@tongji.edu.cn; Tel.: +86-21-65981543
}

Received: 4 July 2019; Accepted: 26 September 2019; Published: 1 October 2019

\begin{abstract}
The intersection of the span shoulder and the scour hole under a pipeline, also called the scour front, can affect the scour hole extension rate and the bearing capacity of the span shoulder, which is associated with pipeline spanning and failure. Studies on scour front evolution are limited due to technical restrictions. In this study, visualization experiments on three-dimensional scour under a pipeline in steady currents were performed to reveal the evolution of the scour front at the beginning of scour process, and the parametric effects on the scour front pattern. The angle of scour front witnessed a steady drop at the start of the scour development process and fluctuated gently thereafter. This can be attributed to the decrease in the blockage effect over time. A gravitational movement was observed on the downstream end of the scour front, which is associated with the variation of fluid pressure along the scour front. The scour front pattern was described by the angle between the scour front and the streamwise direction. Parametric analysis showed that the averaged scour front angle climbs as the Froude number increases and the pipeline embedment drops. This phenomenon can be expounded by the intensified flow deflection near the span shoulder due to the enhancement of the pipeline blockage effect, caused by the ascending Froude number and descending pipeline embedment. The results of this study can be adopted in future mechanism investigations on the scour hole propagation rate and the failure analysis on the span shoulder.
\end{abstract}

Keywords: pipeline scour; three-dimensional scour; span shoulder; steady current; flow pattern

\section{Introduction}

Underwater pipelines are vital connections between oil platforms and refineries. Local scour can appear beneath a pipeline due to excessive local hydrodynamic forces, including currents, waves, and tides. Extension of the local scour along a pipeline triggers pipeline spanning, which can lead to fatigue failure of the pipeline due to vortex-induced vibration. Oil accidents, including pipeline failure, can cause environmental and ecological catastrophes, and bring significant impacts to local areas [1]. Thus, local scour under a pipeline has been the subject of extensive research efforts.

Many investigations have focused on the two-dimensional scour under a pipeline, wherein the currents or waves are assumed to propagate towards the pipeline perpendicularly and the properties of the pipeline and the sediment are supposed to be identical along the pipeline [2]. These investigations have focused on the mechanism of the onset of scour [3,4], the equilibrium scour depth [5-7], the time scale of tunnel erosion [8-10], and field observations and tests [11,12]. Numerical simulation is also widely adopted in researches on the two-dimensional scour hole development process [13-16].

In engineering practice, the scour around the pipeline is actually three-dimensional [2]. Some studies have been conducted on the three-dimensional scour process under a pipeline. Cheng et al. [17] performed a series of experiments on the scour hole extension rate beneath a pipeline 
in steady currents with a series of conductivity probes installed on the bottom of a pipeline. The scour process was divided into two phases in some scenarios, namely the primary phase and the secondary phase. Further investigation found that the two phases can be differentiated by the existence of the pore pressure difference in the sediment on two sides of the pipeline [18]. Later, this research was extended to wave-only conditions and combined wave-current conditions [19]. Wu and Chiew [20] examined the effects of four dimensionless parameters on the scour rate under a pipeline in currents. The scour hole extension rate was revealed to be sensitive to the variation of the embedment ratio, the flow depth, and the Froude number, but this rate is almost independent of the Shields number. Wu and Chiew [21] analyzed the three-dimensional flow pattern adjacent to the span shoulder in steady currents on an immobilized bed. Significant deflection of near-bottom flow in the transverse direction was detected at the edge of the span shoulder. The basic mechanism of the scour hole extension was proposed based on flow pattern analysis. When a steady current approaches a partially embedded pipeline with a scour hole, flow deflection occurs in both vertical and crosswise direction due to the presence of the pipeline, i.e., the blockage effect. In the middle part of the scour hole, the flow separates near the elevation of the pipeline center, and the crosswise deflection does not appear. The flow above the pipeline center accelerates and is guided over the pipeline, and that below is deflected through the scour hole. Near the edge of the scour hole, the flow deflection over the pipeline is more significant. Crosswise deflection of the bottom flow appears, and the bottom flow turns towards the scour hole. At the span shoulder, the entire approaching flow is deflected over the pipeline, and the bottom flow slows, resulting in stagnated flow upstream to the pipeline due to the pipeline blockage effect. Investigations on the scour hole extension rate can also be seen in [22,23].

Scale effects exist in most of the small-scale flume experiments, in which the diameter of the pipeline varies from 5 to $20 \mathrm{~cm}$ [2]. The onset of scour under a pipeline can be basically attributed to seepage failure [3], and the propagation of the scour hole is powered by the excessive local shear stress near the edge of the scour hole [21]. Thus, in experiments on the scour onset and development under a pipeline in steady currents, the scale effects mainly include the effect of Reynolds number, the effect of the pipeline roughness, and the effect of turbulence [24]. Scale effects can influence the flume test results when the results are directly applied to practical engineering, but the influence on the elementary mechanism studies can be smaller. Potential measures reducing the scale effects include increasing the dimensions of the experiment setup and selecting appropriate parameters in the investigation [24], which have been adopted in many recent studies on three-dimensional scour [17-23] with convincing results.

Three-dimensional scour under a pipeline is a complex process that involves the local interaction of flow, sediment, and structure at the end of a span shoulder. Many of the previous studies on three-dimensional scour emphasized the scour extension rate under a pipeline in various conditions $[17,19,20,22,23]$, which is an important part of the interaction. Understanding of the detailed scour process and the mechanism of the flow-pipeline-sediment interaction in scour hole development is limited [18,21], due to limitations of the investigational techniques. Furthermore, the behavior of the sediment at the scour front (i.e., the intersection line of the span shoulder and the scour hole) under the pipeline and the flow inside the scour hole play a more important role in the mechanism of scour hole development, which may help to explain the variation pattern of the scour rate with various parameters studied by [17-23]. However, such studies are few.

The scour front is an important factor in the development of the scour hole, which can also affect the failure of the span shoulder. In scour development, the span shoulder between two scour holes becomes shorter and more pipeline gravity load is exerted on the span shoulder with the extension of the local scour hole. General shear failure occurs at the span shoulder when the critical point of the soil bearing capacity is reached [4]. The geometrical variation of the scour front can thus influence the critical point of the shear failure in the span shoulder, which is a fatal process in the scour hole development and the pipeline spanning. 
The scour process near underwater structures is usually researched with various probes and sensors, like conductivity probes [17,19], acoustic Doppler velocimeters [21], pore pressure sensors [18], and ultrasonic distance sensors [25]. Reports on the scour process with visualization are limited. Zhu et al. [23] measured the scour extension rate beneath a pipeline in steady currents with a miniature camera sealed in a transparent pipeline. Similar techniques can also be seen in other literature $[22,26]$.

In Zhu et al. [22], it can be observed that the scour front deformed with time at the initial stage of scour hole development (Figure 5b-d in [22]). The scour front pattern was also witnessed to vary with the hydrodynamic parameters, like the flow velocity, the flow depth, and the pipeline embedment depth. As is mentioned above, such processes and mechanisms may help to explain the variation in the scour rate and may affect the failure of the span shoulder, but they are rarely reported.

As is depicted in Figure 1, the scour front pattern can evolve in the scour hole expansion process. The scour front pattern also changes with the hydrodynamic parameters. This study aims at revealing the scour front evolution at the initial stage of the pipeline scour process, and analyzing the parametric effects on the scour front pattern. This paper can be regarded as an extension of the investigation by Zhu et al. [22], which focused on the process of onset of scour under a pipeline and the scour hole propagation rate. The basic hypothesis of this study is similar to that of Zhu et al. [22,23]. The evolution of the scour front was observed in a series of visualization tests with a miniature camera sealed in a transparent pipeline. The deformation of the scour front at the initial stage of pipeline scour was observed and analyzed. The elementary mechanism of the scour front deformation was discussed. The pattern of the scour front was depicted by the angle between the scour front and the streamwise direction. A parametric analysis was performed on the effects of the pipeline embedment and the Froude number on the scour front angle, which was selected based on previous reports with similar focus $[17,20,23]$. The flow-pipeline-sediment interaction was discussed thereafter.

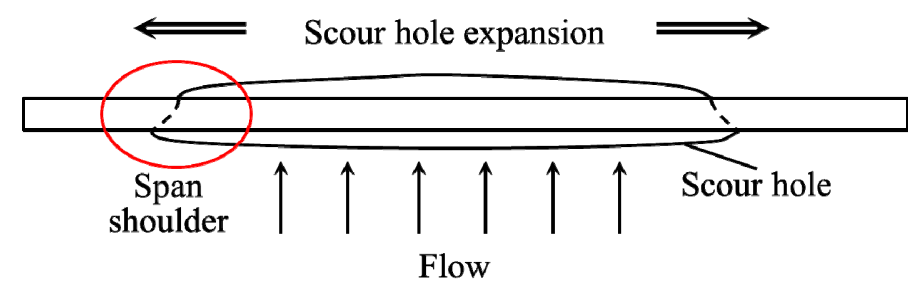

(a)

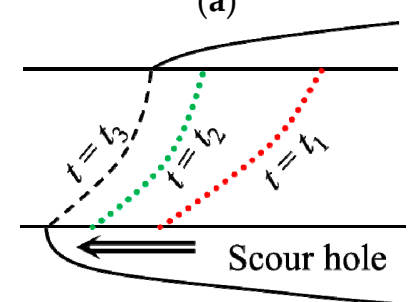

(b)

Figure 1. Aim of investigation of this study: (a) Top view of scour hole development; (b) problem investigated in this study.

\section{Experimental Setup}

The experiments in this study were conducted in a hydraulic flume at the Laboratory of Hydraulic and Harbor Engineering, Tongji University. The flume was $50 \mathrm{~m}$ long, $0.8 \mathrm{~m}$ wide, and $1.2 \mathrm{~m}$ deep (Figure 2). The flume was equipped with a current-generating system, capable of producing a steady current at a flow rate of about $0.5 \mathrm{~m}^{3} / \mathrm{s}$. Two metal fences were installed at the two ends of the flume to ensure a steady current in the flume. The side walls of the flume were made of glass for observation in the tests. A sand recess $2.7 \mathrm{~m}$ long and $1.0 \mathrm{~m}$ deep was set $20 \mathrm{~m}$ downstream of the flume entrance. The side walls and the bottom of the recess were all made of impermeable concrete. The recess was filled with fine sand, of which $d_{50}=0.283 \mathrm{~mm}$ and geometric standard deviation $\sigma_{\mathrm{g}}=\left(d_{84} / d_{16}\right)^{1 / 2}=1.8$. 
A Nortek "Vectrino" high-resolution acoustic Doppler velocimeter (ADV) was placed about $3 \mathrm{~m}$ upstream of the sand recess to monitor the flow velocity at the top of the pipeline $\left(u_{0}\right)$. The range of the velocimeter was $\pm 1.0 \mathrm{~m} / \mathrm{s}$, and the accuracy was $\pm 0.5 \%$ of measured value $\pm 1 \mathrm{~mm} / \mathrm{s}$. The sampling rate was selected to be $100 \mathrm{~Hz}$ in all test cases in this study.

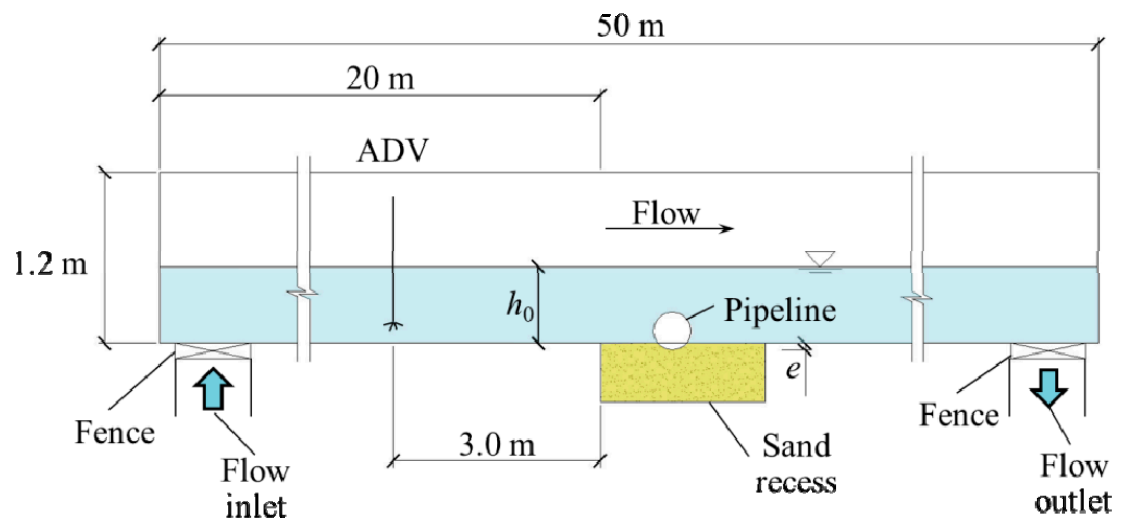

(a)

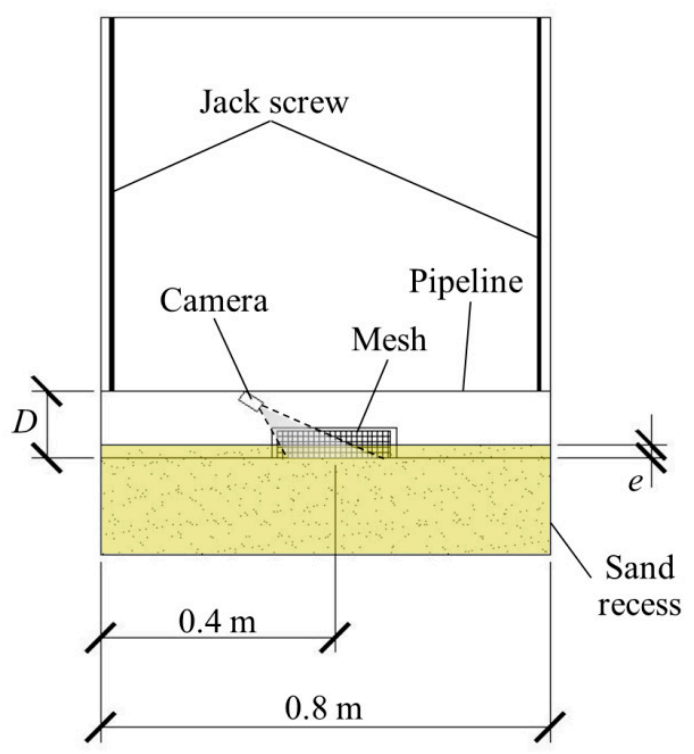

(b)

Figure 2. Experimental setup (not to scale): (a) Experimental flume (side view); (b) setup of model pipeline (cross-section view). Symbols: $h_{0}=$ flow depth; $e=$ pipeline embedment depth; $D=$ pipeline diameter.

The model pipeline was $0.80 \mathrm{~m}$ in length, $0.11 \mathrm{~m}$ in diameter, and was made of transparent acrylic plastic (Figure $2 b$ ). The pipeline was fixed in the middle of the sand recess with two screw bars, so that pipeline movement could be negated in the tests. A 5-mm mesh was printed on the surface of the pipeline, covering most of the camera view. A Logitech C920 mini camera was utilized to take videos in the experiments. The resolution of the camera was $1920 \times 1080$ pixels. The average frame rate of the video clips was $22 \mathrm{fps}$ with a maximum of $30 \mathrm{fps}$. The overall duration of the experiment varied between 2 and $28 \mathrm{~min}$ for different cases. Two ballast blocks were fixed in the pipeline beyond the view of the camera to improve the stability of the model pipeline. The pipeline was sealed on both ends. More details on the model pipeline setup can be found in Zhu et al. [23], where an identical setup was used. Before each test, an initial scour hole was set at about $15 \mathrm{~cm}$ beyond the edge of the camera view so that the scour process would start at the specified point in all cases. If local scour 
occurred elsewhere, the test case would be repeated and the resulting video would be abandoned. Thus, the scour was ensured to start at the specified point, the initial scour hole. Similar techniques can also be seen in $[4,17,19,21]$.

Figure 3a shows a typical scour hole in the camera view. In Figure 3, Lines AB and CD are the initial intersections of the bed profile and the surface of the pipeline. Curve EF is the "scour front", which is the intersection of the span shoulder and the scour hole under the pipeline. It was called the "scour line" in reference [22]. The angle between the streamwise direction and Line EF (angle $\alpha$ in Figure $3 b, c)$ is defined as the scour front angle against the current.

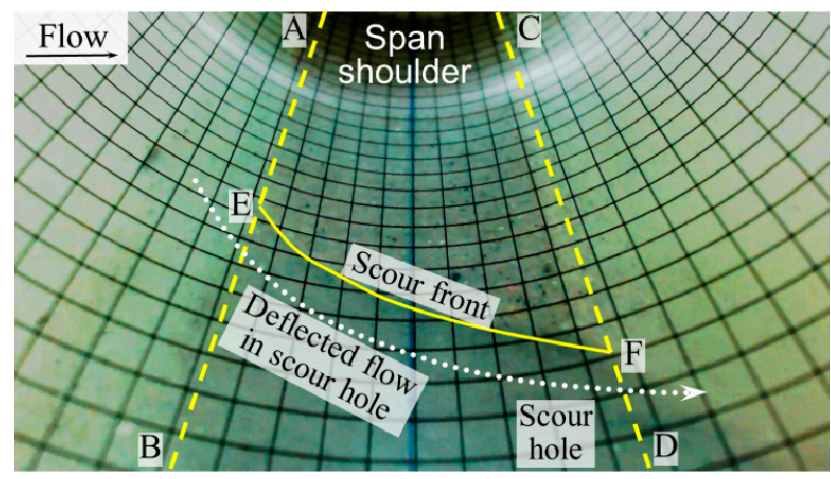

(a)

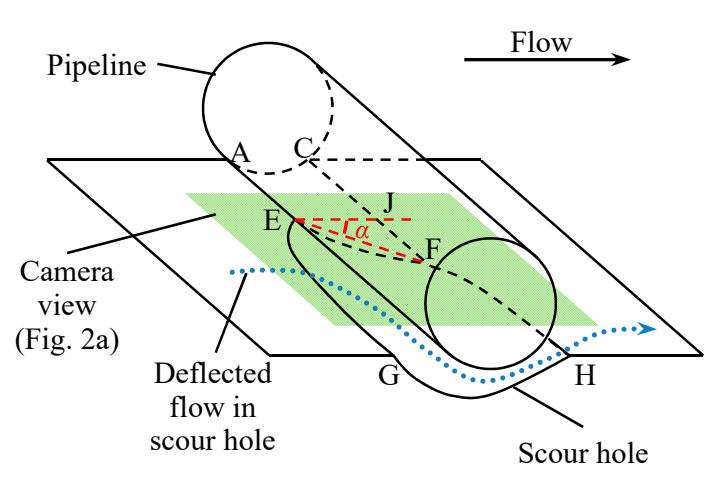

(b)

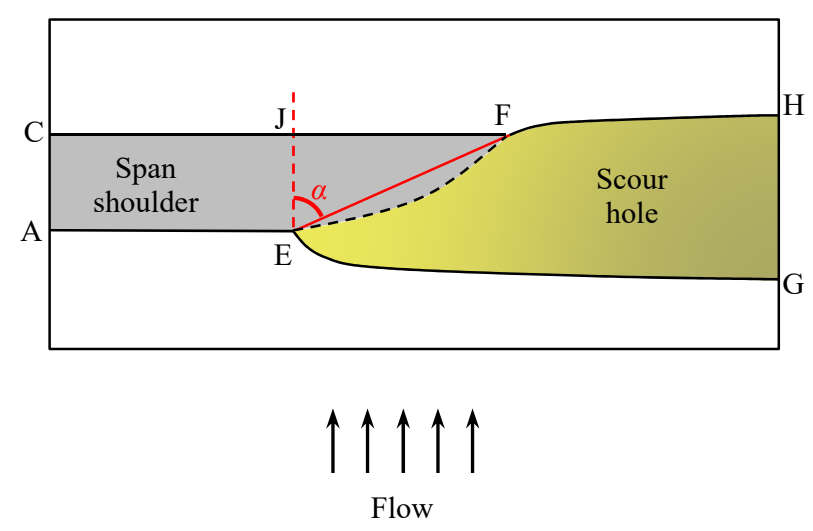

(c)

Figure 3. Photo and sketch of the scour front: (a) Typical view of miniature camera; (b) three-dimensional sketch; (c) top view of the sediment bed (pipeline removed). 
The experimental apparatus in this study was similar to that in an earlier paper [23], and has been proved to be capable of observing the behavior of the scour front and recording the whole process of the scour front evolution. Thus, the apparatus can be regarded as competent for the research question and aim.

As the present study focused on the evolution of the scour front, which mainly reflects the mechanism of scour hole extension under a pipeline and has been rarely investigated before, the key parameters were selected based on previous literature on the scour hole propagation rate $[17,20,23]$. The work in this paper is elementary, so the most important dimensionless parameters studied previously were selected to investigate the parametric effects on the scour front angle against the current: The pipeline embedment ratio $e / D$ (Figure 2) and the Froude number Fr, which can be calculated as:

$$
F r=u_{0} / \sqrt{g h_{0}}
$$

where $u_{0}$ is the undistributed approaching flow velocity at the top of the pipeline; $g$ is the gravitational acceleration; and $h_{0}$ is the flow depth. A total of 16 cases were designed for the parametric analysis on the scour front angle against the current. These cases were divided into two groups, and only one parameter was changed in each group. In group $A$, the pipeline embedment ratio $e / D$ was held constant and the Froude number Fr varied between 0.101 and 0.350. In group B, the Froude number Fr was not changed and the pipeline embedment ratio $e / D$ varied between 0.045 and 0.182 . As is mentioned above, scale effects exist in most of the experiments conducted in laboratories. The experimental setup in this study was similar to those in previous studies on three-dimensional scour under a pipeline to reduce the scale effects. The detailed test conditions for each case are listed in Table 1.

Table 1. Test Conditions.

\begin{tabular}{cccccc}
\hline Group & Case & $\begin{array}{c}\text { Embedment } \\
\text { Ratio } \boldsymbol{e} / \boldsymbol{D}\end{array}$ & $\begin{array}{c}\text { Flow } \\
\text { Depth } \boldsymbol{h}_{\mathbf{0}} / \boldsymbol{D}\end{array}$ & $\begin{array}{c}\text { Depth Averaged Flow } \\
\text { Velocity } \boldsymbol{u}_{\mathbf{0}}(\mathbf{m} / \mathbf{s})\end{array}$ & $\begin{array}{c}\text { Froude } \\
\text { Number } \boldsymbol{F r}\end{array}$ \\
\hline \multirow{6}{*}{ A01 } & 0.045 & 3.64 & 0.200 & 0.101 \\
& A02 & 0.045 & 2.73 & 0.200 & 0.117 \\
& A03 & 0.045 & 3.64 & 0.300 & 0.152 \\
& A04 & 0.045 & 5.45 & 0.400 & 0.165 \\
& A05 & 0.045 & 3.64 & 0.338 & 0.170 \\
& A06 & 0.045 & 2.73 & 0.300 & 0.175 \\
A & A07 & 0.045 & 4.55 & 0.400 & 0.181 \\
& A08 & 0.045 & 3.64 & 0.400 & 0.202 \\
& A09 & 0.045 & 2.73 & 0.350 & 0.204 \\
& A10 & 0.045 & 3.64 & 0.419 & 0.212 \\
& A11 & 0.045 & 2.73 & 0.400 & 0.233 \\
& A12 & 0.045 & 3.64 & 0.600 & 0.303 \\
& A13 & 0.045 & 2.73 & 0.600 & 0.350 \\
\hline \multirow{3}{*}{ B } & A08 & 0.045 & 3.64 & 0.400 & 0.202 \\
& B02 & 0.091 & 3.64 & 0.400 & 0.202 \\
& B03 & 0.136 & 3.64 & 0.400 & 0.202 \\
& B04 & 0.182 & 3.64 & 0.400 & 0.202 \\
\hline
\end{tabular}

\section{Scour Front Deformation at Initial Development}

\subsection{Scour Front Deformation Process}

In previous studies, the scour front was observed to deform at the initial stages of the scour extension process [22]. The evolution of the scour front pattern reflects the complicated interaction mechanism of the local flow, the pipeline, and the bed sediment. To better understand the details in the initial stages of the scour process, a special case was designed to observe the behavior of the scour front by introducing some minor changes to Case A07 in Table 1. In this case, the initial scour hole was 
set at $3 \mathrm{~cm}$ beyond the edge of the camera view, instead of $15 \mathrm{~cm}$ in the cases in Table 1 . The other factors in the experimental setup were all identical to those in Case A07.

Figure 4 shows the frames of the resulting video. The scour front in the previous frame was also plotted as a dashed line in every frame except the first one. As can be seen in Figure 4, the scour front was a smooth and gentle curve, bending slightly towards the scour hole. The scour front angle witnessed a steady drop in the first $10 \mathrm{~s}$ of the recorded period and remained a gentle fluctuation thereafter. The whole scour front entered the camera view at $t=29.713 \mathrm{~s}$, when the scour front inclined steeply towards the scour hole. After that, the scour front retreated gradually. As observed in Figure $4 b, c$, point $F$ retreated faster than point E, and thus the angle of the scour front gradually decreased. The scour front experienced a minor deformation at $t=43.713 \mathrm{~s}$. A tiny gravitational movement occurred on the downstream side of the span shoulder, and the downstream end of the scour front temporarily deflected to the streamwise direction (Figure $4 \mathrm{~d}$ ). Then the scour front became smooth again (Figure 4e) and the scour front pattern remained almost unchanged from $t=46.816 \mathrm{~s}$ to $t=55.072 \mathrm{~s}$, with the scour front angle $\alpha$ fluctuating around $40^{\circ}$ (Figure $4 \mathrm{~g}-\mathrm{i}$ ). The scour front curves were almost parallel to each other.

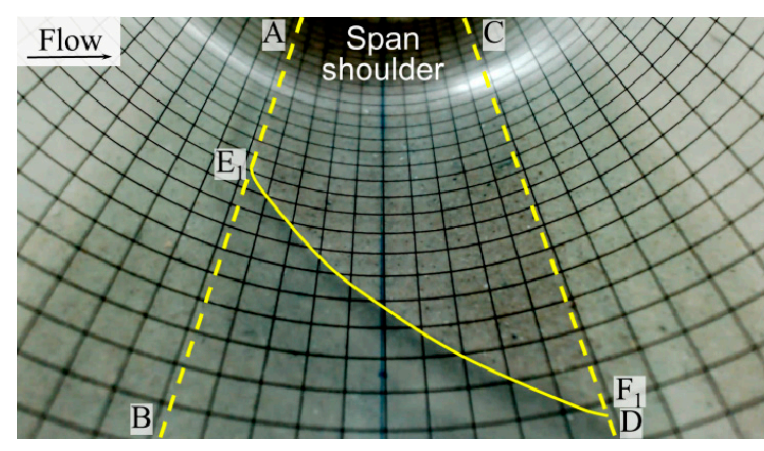

(a)

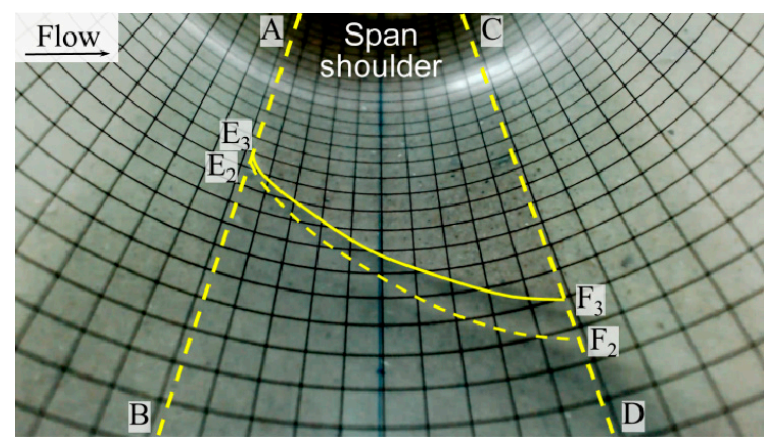

(c)

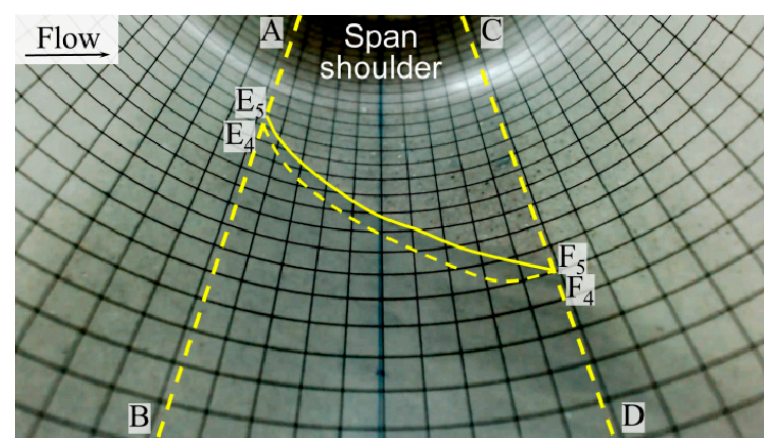

(e)

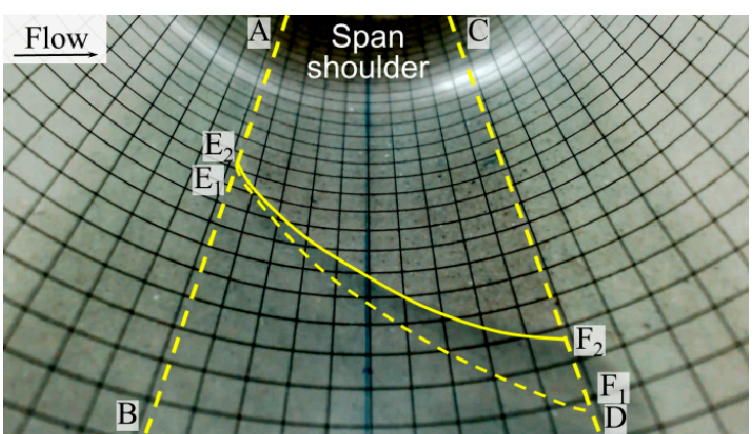

(b)

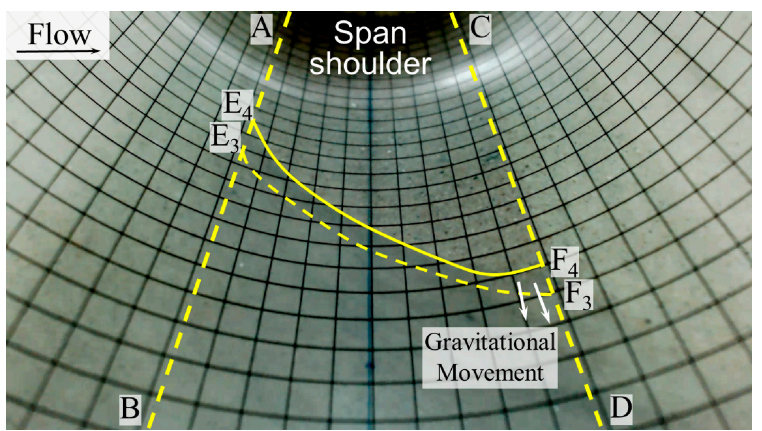

(d)

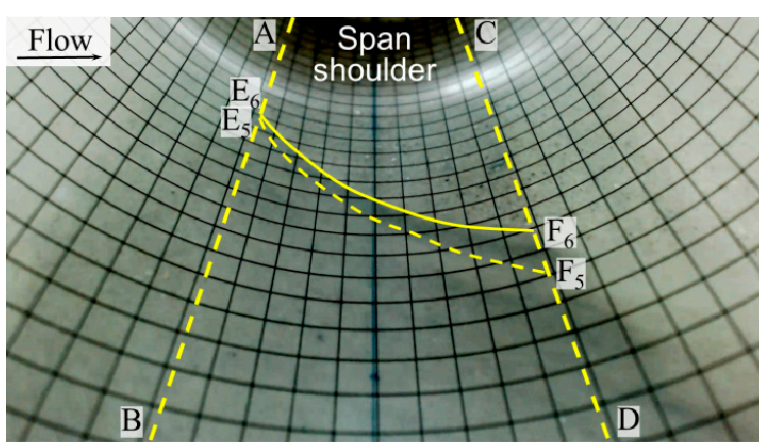

(f)

Figure 4. Cont. 


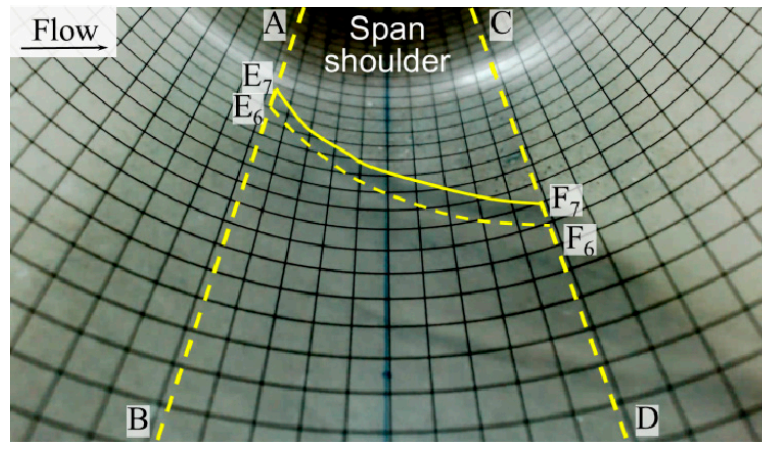

(g)

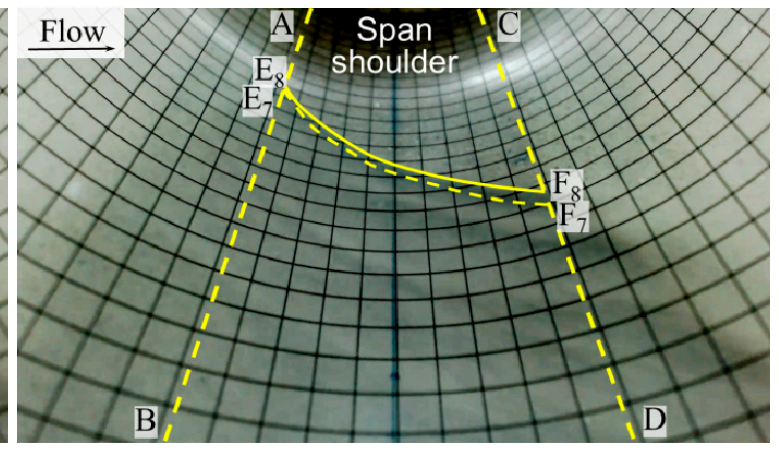

(h)

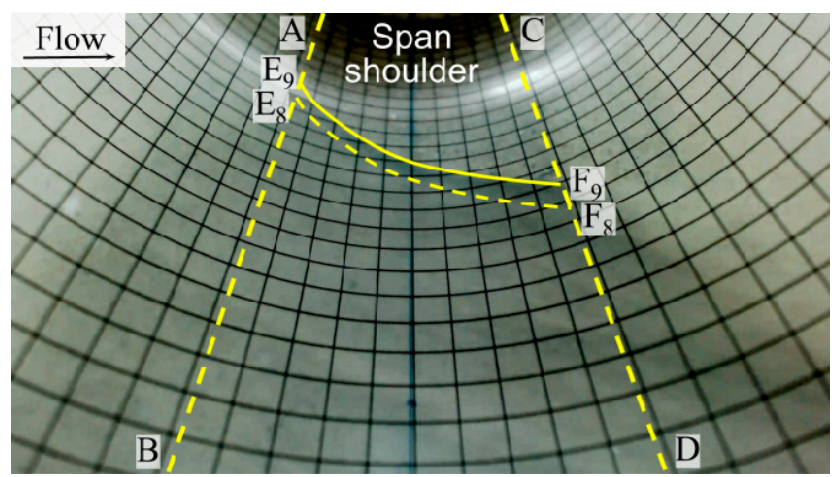

(i)

Figure 4. Video frames of the initial scour process: (a) $t=29.713 \mathrm{~s}$; (b) $t=33.281 \mathrm{~s}$; (c) $t=37.504 \mathrm{~s}$; (d) $t=43.713 \mathrm{~s}$; (e) $t=46.816 \mathrm{~s}$; (f) $t=50.480 \mathrm{~s} ;$ (g) $t=52.816 \mathrm{~s}$; (h) $t=53.904 \mathrm{~s}$; (i) $t=55.072 \mathrm{~s}$.

Figure 5 shows the variation of the scour line (Figure 5a) and the normalized angle between the scour front and the streamwise direction with time (Figure $5 \mathrm{~b}$ ). At approximately $t=30 \mathrm{~s}$, the scour front retreated unevenly on two sides of the pipeline. The downstream end of the scour line developed faster than the upstream end (two green lines in Figure 5a). Thus, the angle of the scour front reduced remarkably. A similar phenomenon can also be seen between $t=46.816 \mathrm{~s}$ and $t=50.480 \mathrm{~s}$ (yellow dotted line and yellow dashed line, respectively, in Figure 5a).

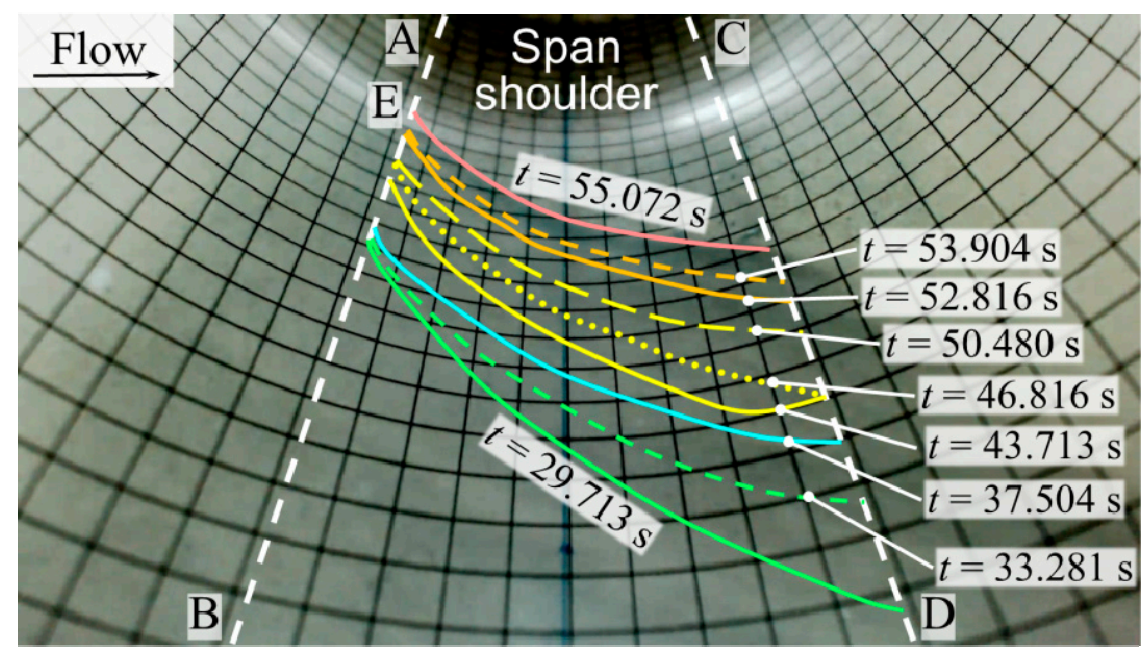

(a)

Figure 5. Cont. 


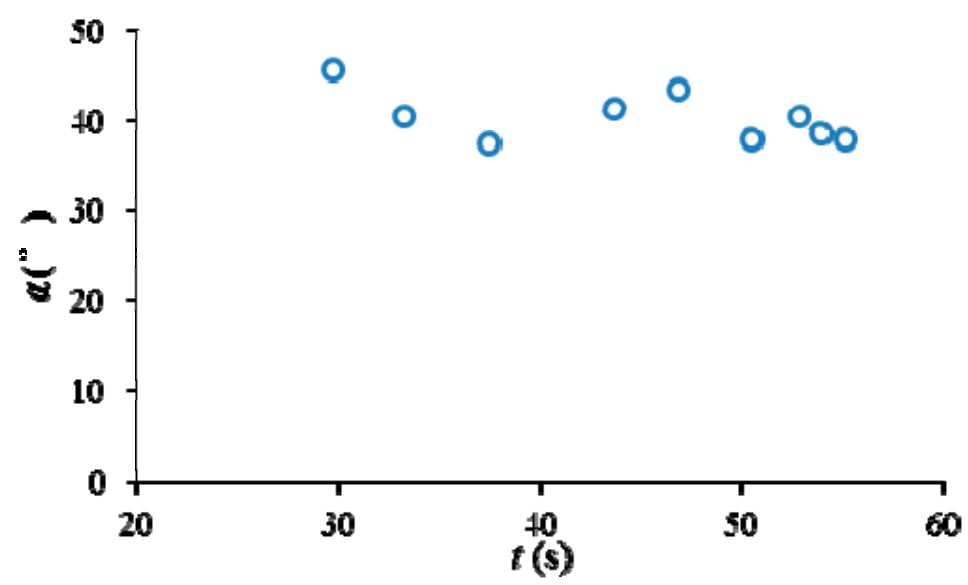

(b)

Figure 5. Variation of the scour front angle with time in the scour process: (a) Variation of the scour front pattern; (b) variation of the scour front angle.

\subsection{Analysis on the Scour Front Deformation}

The deformation of the scour front in the initial stage of scour hole development can be explained as follows.

When a steady flow approaches perpendicularly towards a pipeline suffering local scour, the flow near the edge of the scour hole deflects prominently in the spanwise direction towards the scour hole [21]. The pattern of the scour front is mainly affected by the high velocity flow rushing through the scour hole, so the shape of the scour front can reflect the local flow pattern adjacent to the span shoulder. In addition, as scour front angle is used as an approximate description of the scour front pattern, the scour front angle can serve as a parameter describing the diversion of the approaching flow from the streamwise direction.

At the initial stage of scour hole development, the scour hole was narrow and scour depth was limited. The pipeline blockage effect near the initial scour hole was much more significant than that at a span shoulder developing steadily. The blockage effect of the pipeline can trigger remarkable flow deflection at the span shoulder [21], so flow near the initial scour hole can be diverted more prominently than that at a steadily developing span shoulder. As the scour hole continued extending, the scour hole dimensions rose swiftly, and the pipeline blockage effect at the span shoulder became less significant. Thus, the flow deflection can also be less significant. At this time, the angle of the scour front decreased, and the sediment on the downstream side was eroded more intensively than that on the upstream side (Figure $4 \mathrm{a}-\mathrm{c}$ ). The scour front angle gradually decreased as the influence of the initial scour hole faded. It should be noted that the evolution of the flow pattern near the edge of the scour hole may not be steady, as many other factors can affect the three-dimensional flow in this area, including the potential vortex shedding on the leeside of the pipeline. As a result, the scour front angle witnessed a gentle fluctuation before reaching an approximately steady development (Figure $5 b$ ).

In the frames of the video, the small gravitational movement at the downstream side of the scour front was also noticeable at $t=43.713 \mathrm{~s}$ (Figure $4 \mathrm{~d}$ ). Similar gravitational movements also appeared in cases with large pipeline embedment depths (e.g., Cases B02, B03, and B04 in Table 1). The gravitational movement at the scour front can accelerate the scour development process. Such gravitational movements occurred at the downstream end of the scour front in most scenarios. A typical gravitational movement at the scour front covered about 0.5 to $2.0 \mathrm{~cm}$ on the scour front for different cases in this study. A possible cause to the gravitational movement may be the variation of the hydrodynamic pressure on the span shoulder.

After the deflected flow enters the scour hole, the flow congests and accelerates gradually along the streamwise direction as the scour hole becomes narrower. As the flow in the scour hole satisfies the Bernoulli's Equation, the fluid pressure keeps dropping along the streamwise direction to compensate 
for the velocity increase and the water head loss. Thus, the fluid pressure in the scour hole reaches a minimum value at the scour hole exit. In Figure $4 \mathrm{~d}$, the slope angle at the edge of the span shoulder is larger than the repose angle of saturated fine sand underwater. Thus, slope stability at the edge of the span shoulder may partially rely on the lateral fluid pressure of the flow through the scour hole. When the lateral fluid pressure on the span shoulder is smaller, the gravitational movement is more likely to appear. Thus, gravitational movements usually occur on the downstream side of the scour hole. When the pipeline embedment is larger, the gravitational movement tends to appear more frequently and the coverage of the gravitational movement also tends to be larger. This can be attributed to the remarkable increase in the angle of the slope at the exit of scour hole as the pipeline embedment rises.

\section{Effects on the Scour Front Angle against the Flow}

In this section, the parametric effects on the scour front are analyzed to better understand the flow pattern near the edge of a scour hole, which may help to interpret the variation of the scour rate with various parameters.

\subsection{Effects of the Froude Number}

Tests in Group A focused on the effect of the Froude number on the scour front, with the Froude number varying from 0.101 to 0.350 . The pipeline embedment was held constant, i.e., $e / D=0.045$. Figure 6 depicts the variation of the scour front angle against the flow $\alpha$ with the Froude number $F r$. As the scour front angle may fluctuate gently with time, the time averaged scour front angle was adopted in the analysis. In general, the scour front angle against the flow climbed approximately linearly with the Froude number within the tested range of parameters.

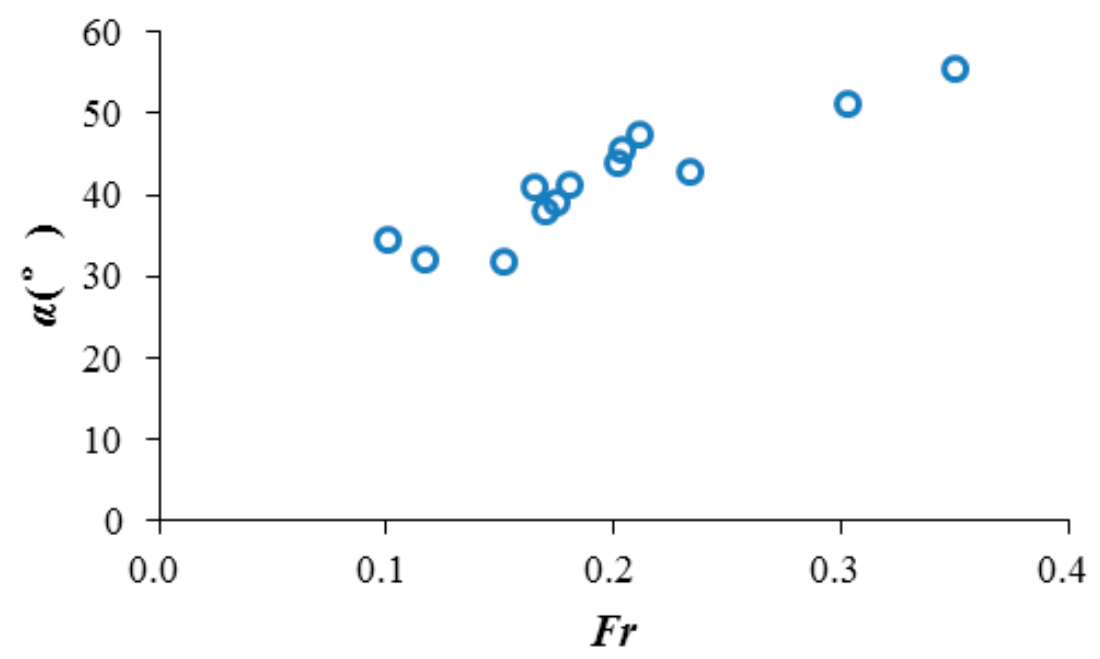

Figure 6. Variation of scour front angle with Froude number.

\subsection{Effects of the Pipeline Embedment Ratio}

Tests in Group B focused on the effect of the pipeline embedment on the scour front, with the pipeline embedment varying from 0.045 to 0.182 . The Froude number was held constant, i.e., $F r=0.202$. Figure 7 demonstrates the variation of the scour front angle with the pipeline embedment. The pipeline embedment was normalized to be the ratio of the embedment depth to the pipeline diameter $e / D$. The time-averaged scour front angle dropped almost linearly with the increase of the pipeline embedment ratio when $e / D<0.15$. When $e / D>0.15$, the descent rate of the normalized scour front angle showed a decreasing trend. 


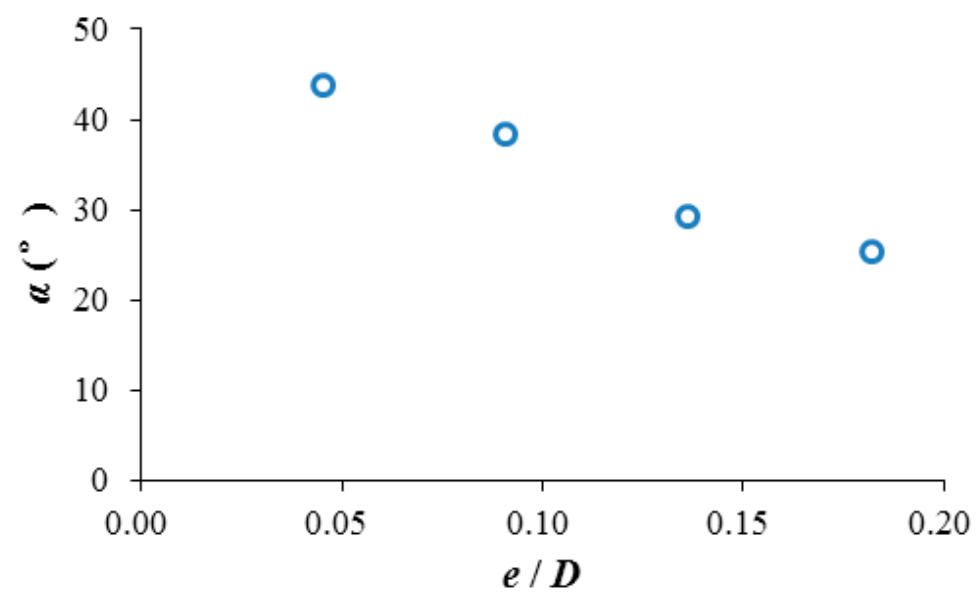

Figure 7. Variation of scour front angle with pipeline embedment.

\subsection{Discussion of the Effects on the Scour Front Angle}

Figures 6 and 7 depict an increase of the scour front angle $\alpha$ with increasing Froude number and decreasing pipeline embedment, which can be expounded as follows. According to Equation (1), the increasing Froude number indicates an increase in the flow velocity, a decrease in the flow depth, or both. As the increasing flow velocity, the decreasing flow depth, and the dropping pipeline embedment can all intensify the flow blockage effect of the pipeline [27,28], the stagnated flow on the upstream side of the pipeline can be enhanced by increasing Fr or decreasing $e / D$. The stagnated flow near the edge of the span shoulder can cause flow deflection towards the scour hole [21]. The flow deflection can be more significant as the flow blockage effect intensifies. The increasing Froude number and decreasing pipeline embedment can strengthen the flow deflection and thus increase the scour front angle.

It should be noted that the linear increasing trend of $\alpha$ with the Froude number in Figure 6 is confined within the tested range of parameters in this study. As revealed in [23], the development of a scour hole stops when the Froude number is below the critical values for scour hole extension. Thus, the evolution of the scour front also stops.

In this elementary study on the mechanism of the scour front evolution, the parametric analysis emphasizes two major parameters: The pipeline embedment ratio and the Froude number. Actually, the variation of the scour front is a dynamic process of flow, seepage, and sediment. Other factors can also influence the variation of the scour front, including the property of the sediment, the seepage flow in the span shoulder, the flow incident angle, and the sediment transportation capacity of flow. The role these factors play in the evolution of scour needs to be analyzed and discussed in detail in future investigations.

\section{Conclusions}

This study presents a series of visualization tests on the three-dimensional scour process beneath a pipeline using a miniature camera to better understand the details in the pipeline scour propagation mechanism. The scour front evolution in the initial stage of scour hole development was directly observed and analyzed. The parametric effects were investigated on the averaged angle between the scour front and the streamwise direction, an indicator of the scour front pattern. The elementary mechanism of the scour front deformation was also discussed. The results in the present study can help to explain the variation mechanism of the scour rate of pipelines, and may also help in future studies on the failure of the span shoulder.

The scour front development was observed at the initial stage of a scour hole. During the initial stages of scour hole development, the scour front inclined steeply to the scour hole and the scour front angle was remarkably large. Over time, the angle of the scour front gradually decreased, and then gently fluctuated. The drop in the scour front can be associated with a decrease in the pipeline blockage 
effect. A gravitational movement was witnessed on the downstream end of the scour front, which can be attributed to a variation in the hydrodynamic pressure along the scour front.

The scour front angle increased with increasing Froude number and decreasing pipeline embedment. With increasing Froude number and decreasing pipeline embedment, the blockage effect of the pipeline was enhanced, thus intensifying the flow deflection at the span shoulder, and the scour front angle increased as well.

Despite of the achievements in this elementary study, further studies are needed to better understand the detailed mechanism of scour front evolution, which involves the complex flow-pipeline-sediment interaction near the edge of the scour hole.

Author Contributions: Conceptualization, L.X., Y.Z., and T.-C.S.; funding acquisition, L.X. and Y.Z.; investigation, L.X., Y.Z., and T.-C.S.; methodology, L.X., Y.Z., and T.-C.S.; resources, L.X. and Y.Z.; supervision, L.X.; visualization, L.X. and Y.Z.; writing—original draft, Y.Z.; writing—review and editing, L.X., Y.Z., and T.-C.S.

Funding: This research was funded by the National Natural Science Foundation of China, grant numbers 11172213 and 51479137, and the China Scholarship Council, grant number 201806260166.

Acknowledgments: The authors are grateful to Ting Lin, who was an undergraduate of College of Civil Engineering, Tongji University, for the generous assistance in the experiments.

Conflicts of Interest: The authors declare no conflicts of interest. The funders had no role in the design of the study; in the collection, analyses, or interpretation of data; in the writing of the manuscript; or in the decision to publish the results.

\section{References}

1. Zafirakou, A.; Themeli, S.; Tsami, E.; Aretoulis, G. Multi-Criteria Analysis of Different Approaches to Protect the Marine and Coastal Environment from Oil Spills. J. Mar. Sci. Eng. 2018, 6, 125. [CrossRef]

2. Fredsøe, J. Pipeline-seabed interaction. J. Waterw. Port Coast. Ocean Eng. 2016, 142, 03116002. [CrossRef]

3. Chiew, Y.M. Mechanics of Local Scour around Submarine Pipelines. J. Hydraul. Eng. 1990, 116, 515-529. [CrossRef]

4. Sumer, B.M.; Truelsen, C.; Sichmann, T.; Fredsøe, J. Onset of scour below pipelines and self-burial. Coast. Eng. 2001, 42, 313-335. [CrossRef]

5. Chiew, Y.M. Prediction of maximum scour depth at submarine pipelines. J. Hydraul. Eng. 1991, 117, $452-466$. [CrossRef]

6. Postacchini, M.; Brocchini, M. Scour depth under pipelines placed on weakly cohesive soils. Appl. Ocean Res. 2015, 52, 73-79. [CrossRef]

7. Dogan, M.; Aksoy, A.O.; Arisoy, Y.; Guney, M.S.; Abdi, V. Experimental investigation of the equilibrium scour depth below submerged pipes both in live-bed and clear-water regimes under the wave effect. Appl. Ocean Res. 2018, 80, 49-56. [CrossRef]

8. Fredsøe, J.; Sumer, B.M.; Arnskov, M. Time scale for wave/current scour below pipelines. Int. J. Offshore Polar Eng. 1992, 2, 13-17.

9. Zhang, Q.; Draper, S.; Cheng, L. Scour below a subsea pipeline in time varying flow conditions. Appl. Ocean Res. 2016, 55, 151-162. [CrossRef]

10. Zang, Z.; Tang, G.; Cheng, L. Time scale of scour below submarine pipeline under combined waves and currents with oblique incident angle. In ASME 2017, Proceedings of the 36th International Conference on Ocean, Offshore and Arctic Engineering, Trondheim, Norway, 25-30 June 2017; ASME: New York, NY, USA, 2017; V009T10A019.

11. Leckie, S.H.; Draper, S.; White, D.J.; Cheng, L.; Fogliani, A. Lifelong embedment and spanning of a pipeline on a mobile seabed. Coast. Eng. 2015, 95, 130-146. [CrossRef]

12. Leckie, S.H.; Mohr, H.; Draper, S.; McLean, D.L.; White, D.J.; Cheng, L. Sedimentation-induced burial of subsea pipelines: Observations from field data and laboratory experiments. Coast. Eng. 2016, 114, 137-158. [CrossRef]

13. Liang, D.; Cheng, L.; Li, F. Numerical modeling of flow and scour below a pipeline in currents: Part II. Scour simulation. Coast. Eng. 2005, 52, 43-62. [CrossRef] 
14. Zang, Z.; Cheng, L.; Zhao, M.; Liang, D.; Teng, B. A numerical model for onset of scour below offshore pipelines. Coast. Eng. 2009, 56, 458-466. [CrossRef]

15. Fuhrman, D.R.; Baykal, C.; Sumer, B.M.; Jacobsen, N.G.; Fredsøe, J. Numerical simulation of wave- induced scour and backfilling processes beneath submarine pipelines. Coast. Eng. 2014, 94, 10-22. [CrossRef]

16. Foo, C.S.X.; Liao, C.; Chen, J. Two-Dimensional Numerical Study of Seabed Response around a Buried Pipeline under Wave and Current Loading. J. Mar. Sci. Eng. 2019, 7, 66. [CrossRef]

17. Cheng, L.; Yeow, K.; Zhang, Z.; Teng, B. Three-dimensional scour below offshore pipelines in steady currents. Coast. Eng. 2009, 56, 577-590. [CrossRef]

18. Wu, Y.; Chiew, Y.M. Mechanics of pipeline scour propagation in the spanwise direction. J. Waterw. Port Coast. Ocean Eng. 2014, 141, 04014045. [CrossRef]

19. Cheng, L.; Yeow, K.; Zang, Z.; Li, F. 3D scour below pipelines under waves and combined waves and currents. Coast. Eng. 2014, 83, 137-149. [CrossRef]

20. Wu, Y.; Chiew, Y.M. Three-dimensional scour at submarine pipelines. J. Hydraul. Eng. 2012, 138, 788-795. [CrossRef]

21. Wu, Y.; Chiew, Y.M. Mechanics of three-dimensional pipeline scour in unidirectional steady current. J. Pipeline Syst. Eng. Pract. 2013, 4, 3-10. [CrossRef]

22. Zhu, Y.; Xie, L.; Liang, X. Scour patterns below pipelines and scour hole expansion rate. In Scour and Erosion, Proceedings of the 8th International Conference on Scour and Erosion, Oxford, UK, 12-15 September 2016; Harris, J., Whitehouse, R., Moxon, S., Eds.; CRC Press: Leiden, The Netherlands, 2016; pp. 387-394.

23. Zhu, Y.; Xie, L.; Su, T.C. Visualization tests on scour rates below pipelines in steady currents. J. Hydraul. Eng. 2019, 145, 04019005. [CrossRef]

24. Sumer, B.M.; Fredsøe, J. The Mechanics of Scour in the Marine Environment; World Scientific Publishing: Singapore, 2002; pp. 111-113.

25. Guan, D.; Melville, B.W.; Friedrich, H. Live-bed scour at submerged weirs. J. Hydraul. Eng. 2015, 141, 04014071. [CrossRef]

26. Sumer, B.M.; Hatipoglu, F.; Fredsøe, J. Wave scour around a pile in sand, medium dense, and dense silt. J. Waterw. Port Coast. Ocean Eng. 2007, 133, 14-27. [CrossRef]

27. Chiew, Y.M. Flow around horizontal circular cylinder in shallow flows. J. Waterw. Port Coast. Ocean Eng. 1991, 117, 120-135. [CrossRef]

28. Zhu, Y.; Xie, L. Numerical analysis of flow effects on water interface over a submarine pipeline. In Resources, Environment and Engineering II, Proceedings of the 2nd Technical Congress on Resources, Environment and Engineering, Hong Kong, China, 25-26 September 2015; Xie, L., Ed.; Taylor \& Francis Group: London, UK, 2016; pp. 99-104.

(C) 2019 by the authors. Licensee MDPI, Basel, Switzerland. This article is an open access article distributed under the terms and conditions of the Creative Commons Attribution (CC BY) license (http://creativecommons.org/licenses/by/4.0/). 